\title{
The Application of Purchasing Chessboard on Supplier Management and Evaluation against the Background of Big Data
}

\author{
Jianghui Liu* \\ Education Technology Center, Experimental Teaching Center \\ Guangdong University of Foreign Studies \\ Guangzhou, China \\ 247031690@qq.com
}

\author{
Fumin Yang \\ School of Business \\ Guangdong University of Foreign Studies \\ Guangzhou, China
}

\begin{abstract}
In the process of supplier evaluation, enterprises used to focus merely on comparing candidate suppliers' performances. In this paper, a systematic supplier evaluation framework is proposed to efficiently address supplier management in the Big Data environment by integrating Supplier Evaluation Indexes and the Purchasing Model. The framework models supplier evaluation in a hierarchical way. The study evaluates candidate suppliers based on Supplier Evaluation Indexes by means of data analysis. Then the study makes further evaluation and selection based on the Purchasing Chessboard for suppliers passing the evaluation index assessment. The proposed framework shows efficiency and rationality in supplier evaluation and provided direction for enterprises to select suppliers.
\end{abstract}

Keywords-Big Data; Supplier evaluation indexes; The Purchasing Chessboard

\section{INTRODUCTION}

For today's enterprises, suppliers have played an increasingly significant role in the entire operation. Selecting suitable and high-quality supplier is beneficial to provide superior material support for the whole supply chain, enhance customer satisfaction and consolidate market position. However, at present the level of supplier management in our country is relatively low. Most enterprises still only focus on price and pursue short-term benefits. Their primary goal is to maximize their own interests.

As a result, low price has been the only standard for enterprises selecting suppliers to reduce total costs. They don't consider mutual benefit between two sides and maximize supply chain performance as the main target. At the same time, they don't pursue long-term cooperation with suppliers. In short, there exist such problems as imperfection of evaluation standard and lack of excellent selection mechanism [1].

With the development of informationization and networking, the application of Big Data gains more and more popularity. Supply chain also places more and more emphasis on Big Data. Enterprises conduct a series of data analysis, and establish a supply chain Big Data platform, from which they extract and integrate information to formulate evaluation indexes so as to select suitable suppliers. It's a good way to optimize supply chain management and improve enterprise performance. In a Big Data environment, it has been a trend of using data analysis processing method to quantify supplier information in order to evaluate and select suppliers effectively [2].

\section{SUPPLIER EVALUATION INDEXES}

Through analysis of market condition and internal environment, enterprises establish supplier selection target at first. Then they assess suppliers based on Supplier Evaluation Indexes initially. A scientific supplier evaluation index is helpful for enterprises to select high-quality suppliers and establish strategic partnerships with them so as to improve enterprise competitiveness [3]. In this paper, we divide Supplier Evaluation Indexes into two major dimension, as shown in Figure 1. 


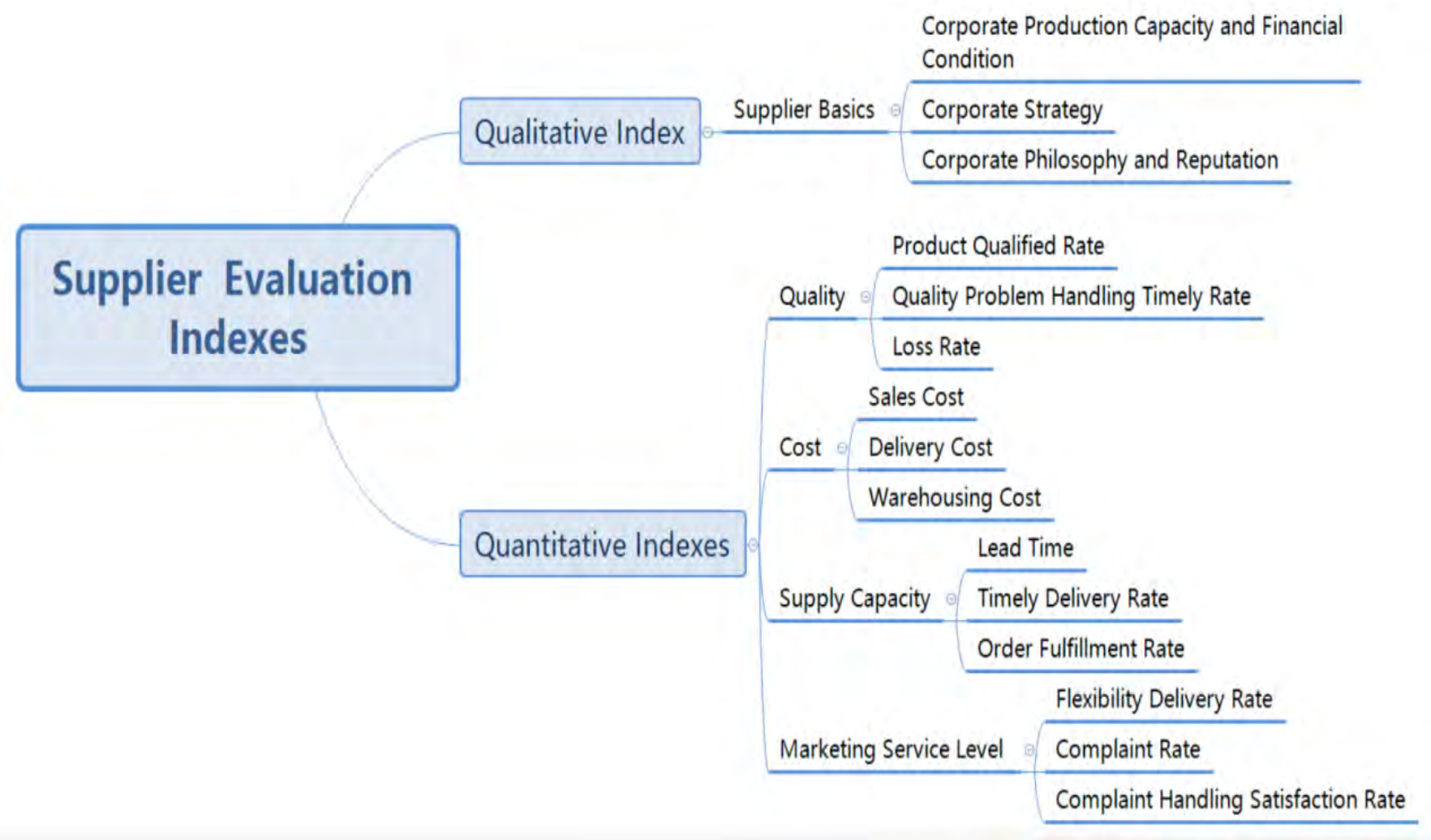

Fig. 1. Supplier evaluation index.

The first index is qualitative index, which mainly refers to the basic condition of suppliers. It includes corporate production capacity and financial condition, corporate strategy as well as corporate philosophy and reputation. Understanding supplier basics is favorable for enterprises to master general condition of suppliers as a whole.

The second index is quantitative index, including quality, cost, supply capacity and marketing service level. Such four indexes are key aspects of evaluating suppliers [4]. We will describe these four dimensions below in details.

- The Quality. The quality includes product qualified rate, quality problem handling rate and loss rate. According to the assessment of such specific indicators mentioned above, quality of products provided by suppliers and accuracy of quality problems handling are examined.

- The Cost. The quoted price offered by suppliers is checked by calculating total costs of suppliers, which mainly constitutes sales, transportation and warehousing cost.

- The Capacity. It is examined by the following three indicators: lead time, timely delivery rate and order fulfillment rate.

- The Marketing service level. It is measured by flexibility delivery capability, complaint rate and complaint handling satisfaction rate to check suppliers service level.
Supplier Evaluation Indexes process each supplier qualitatively and quantitatively. As the first step of evaluation, the qualitative index is to grasp basic situation of suppliers. While quantitative index can reduce or even avoid appearance of subjective assumptions. The combination of qualitative and quantitative indexes is advantageous to assess suppliers more comprehensively and optimize supplier structure. In practical application, enterprises should grasp a general understanding of basic condition of suppliers in the first place. Those suppliers with poor reputation or lack of fund should be eliminated to avoid unnecessary trouble in the later period. As for those satisfactory suppliers after basic understanding, enterprises can carry out further selection by examining their quality, cost, supply capacity and marketing service level [5]. The specific scores or grade weights of each category in quantitative indexes should be determined considering enterprise specific situation. In practice, enterprise should choose suitable indexes to evaluate and select suppliers based on its own strategic objectives, market environment and actual situation.

\section{THE PURCHASING CHESSBOARD AND THE APPLICATION}

\section{A. The Purchasing Chessboard}

To cope with constantly changing market challenges as well as helping companies carry out strategic procurement management, after doing research on more than 500 purchasing projects performed worldwide over three years, A.T. Kearney developed The Purchasing Chessboard. It is a framework to address every supply and demand market condition [6]. 
Based on supply and demand power comparison, the Purchasing Chessboard uses index positioning method to classify different types of suppliers, distinguish their characteristics, and comprehensively compare strength and competitiveness between suppliers and companies. It serves as the basis for enterprises to select the best supplier.

\section{B. The Purchasing Chessboard Application}

The Purchasing Chessboard model is a systematic procurement strategy system. It constitutes 64 methods, each representing a stand-alone, differentiating way to work with suppliers to reduce costs and increase value. These methods are derived from 16 approaches and four purchasing strategies. This model is mainly used to provide ideas for making purchasing strategies. The top-level procurement strategy, which connects with enterprise strategy, is decided by the top leader. The middle-level procurement plan and 64 specific methods serve as the basis for executives taking action. As a reference benchmark for enterprise purchasing, the Purchasing
Chessboard is helpful for enterprises to select suitable suppliers, cope with various challenges in purchasing decisions and make correct purchasing decisions [7].

\section{The PURCHASING CHESSBOARD-SUPPLIER SELECTION FRAMEWORK BASED ON BIG DATA}

\section{A. The Purchasing Chessboard-Supplier Selection Framework Design}

In an era of supply chain, enterprises pay more and more attention to Big Data. It's an effective method for enterprises to evaluate and select suppliers by data analysis. In this paper, integrating supplier evaluation index and the Purchasing Chessboard model, we design The Purchasing ChessboardSupplier Selection Framework. The framework design is shown in Figure 2.

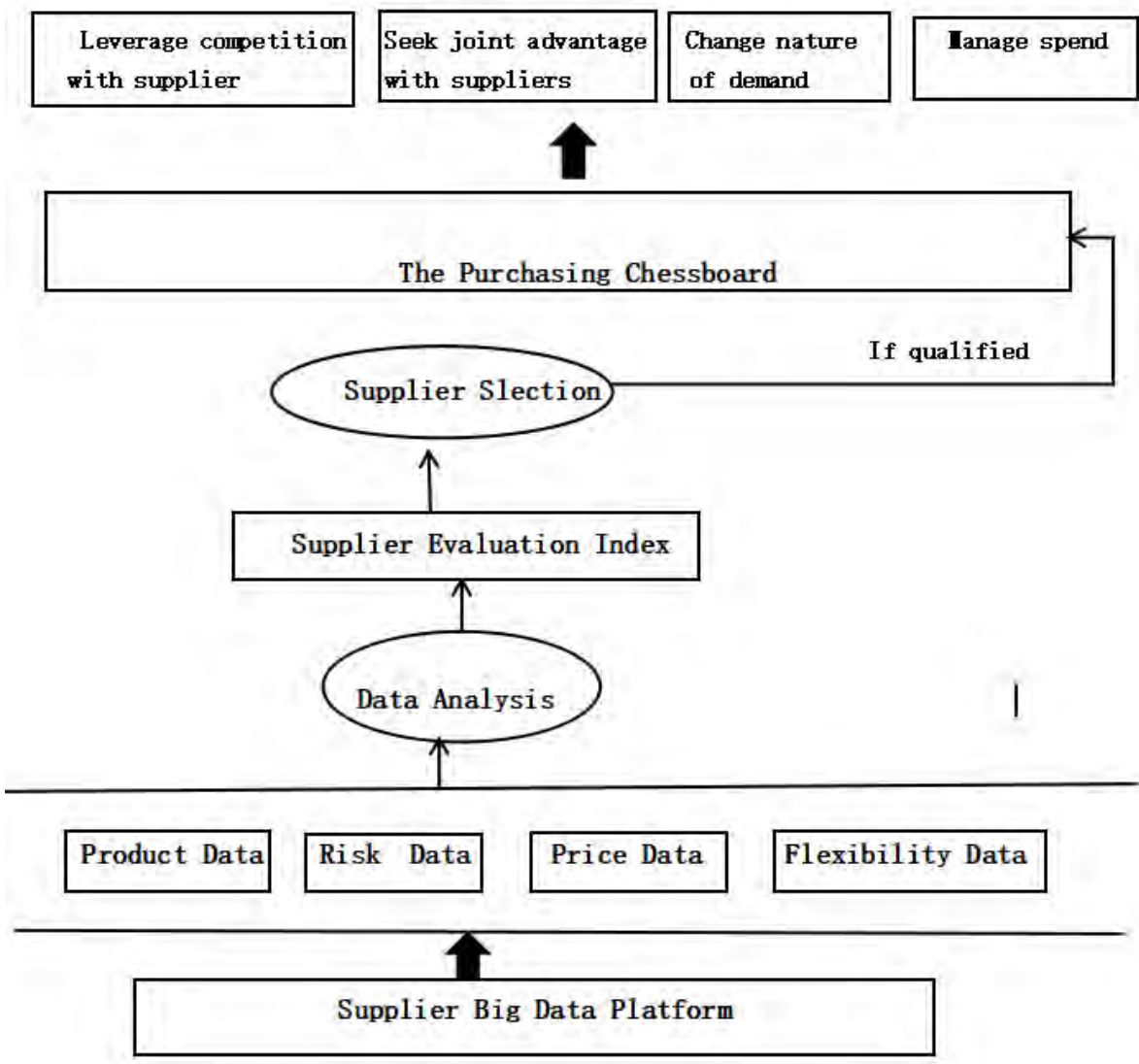

Fig. 2. The purchasing Chessboard-Supplier selection framework.

Based on Big Data platform, the framework divides supplier evaluation into two steps. Supplier Evaluation Indexes are the first threshold of supplier admission qualification. Only those suppliers who have passed supplier evaluation index assessment can have the opportunity to further evaluation for establishing collaborative relationship. The Purchasing Chessboard-Supplier Selection Framework breaks through shortcomings that enterprises used to focus on comparing candidate suppliers' performances. Also, it effectively reduces or even avoids enterprises limited by suppliers happening in the later cooperation. To a certain extent, the framework improves supplier management status and enhances supply chain performance. 
As a result of single and ambiguous supplier evaluation index, enterprises are unfamiliar with suppliers, which makes supplier selection difficult. It's quite important to gather supplier information and establish the supplier Big Data platform. The Big Data platform mainly consists of product data, risk data, price data and asset data. Product data refers to related product information including product type, name and other related information. Risk data is used to evaluate supplier reliability by measuring on time delivery rate. Price data is the quotation provided by suppliers. Asset data mainly refers to supplier's financial situation, including cash flow, capital turnover rate and other related information. The supplier Big Data platform integrates supplier data and supplier evaluation index successfully. Enterprises are able to evaluate and select suppliers on this Big Data platform.

Under the Big Data environment, enterprises gather supplier-related data such as product data, risk data and price data through supplier Big Data platform. The next step is to conduct a series of data analysis on candidate suppliers, followed by preliminary evaluation according to supplier evaluation index. For those suppliers who have passed supplier evaluation index assessment, enterprises will evaluate them again according to the Purchasing Chessboard. Based on supply and demand power comparison, the Purchasing Chessboard uses index positioning method to divide into four categories. Each category is matched with one strategy respectively. According to four strategies under the model: leverage competition with supplier, seek joint advantages with suppliers, change nature of demand and manage spend, the ultimate partner will be determined.

\section{B. Four Strategies of the Purchasing Chessboard}

There are four different purchasing schemes under four strategies of the Purchasing chessboard model. In actual operation, enterprises should combine and use these purchasing schemes flexibly to choose suitable suppliers according to their own actual conditions.

\section{1) Leveraging competition among suppliers}

This strategy is the most basic strategy, which is particularly popular when buying in a high-demand, lowsupply market. There are four main procurement levers: tendering, reviewing supplier's prices, leveraging global supplier markets and enforcing target prices. Under this strategy, in order to obtain the same value of products and services at a lower price, enterprises usually provoke competition among candidate suppliers and seek suppliers with lower quotations.

\section{2) Seeking joint advantage with suppliers}

This strategy applies to the situation where suppliers and buyers have equal market power. In these situations, the focus should be on value chain management, value chain partnership, integrated operations planning and cost partnership. Considering compatibility of philosophy and culture between two sides, enterprises should give priority to strengthen exchanges, carry out technological cooperation, realize information sharing and establish value partnership. Such partnership can reduce costs while also generating value.

\section{3) Changing the nature of demand}

This strategy is applicable to the situation where suppliers occupy a dominant position in the market. When companies develop long-term partnerships with their key suppliers, these suppliers soon become indispensable. As a result, the power between suppliers and buyers will lean towards suppliers. In such market, the objective is to change the nature of demand. Companies can change the nature of demand to find alternative suppliers or strive to expand new suppliers. This is done by innovation breakthrough, re-specification, risk management and technical data mining.

\section{4) Rationalization of management expenditure}

Managing spend is particularly useful in low-demand, lowsupply markets. In such situation, the focus should be on cosourcing, commercial data mining, demand management and volume bundling. In the process of selecting suppliers, companies should try to realize transparency in spend behavior, reduce unnecessary expenditure and reduce costs.

\section{CONCLUSiOn}

Supplier selection and evaluation are the core of supply chain operation. Selecting suitable supplier is conducive to reducing supplier management cost, improving the whole supply chain and enhancing company competitiveness. In the time of Big Data, whoever owns and makes full use of Big Data will seize the opportunity of the market. In this paper, we integrate supplier evaluation index and the Purchasing Chessboard model to provide direction for enterprises to evaluate and select suppliers. It should be noted that supplier evaluation index is unchanging. It shall be implemented according industry characteristics as well as modified in the process of practical operation.

\section{REFERENCES}

[1] F. Samanlioglu. "An intelligent approach to supplier evaluation in automotive sector," Journal of Intelligent Manufacturing, vol. 27, pp. 889-903, April 2016.

[2] G. Wang, A. Gunasekaran, E. W. T. Ngai, and T. Papadopoulos, "Big Data analytics in logistics and supply chain management: Certain investigations for research and applications," International Journal of Production Economics, vol. 176, pp. 98-110, 2016.

[3] M. Y. Liao, C. W. Wu, and J. W. Wu. "Fuzzy inference to supplier evaluation and selection based on quality index: a flexible approach," Neural Computing \& Applications, vol. 23, pp. S117-S127, Junuary 2013.

[4] M. Tavana, A. Fallahpour, D. D. Caprio, and F. J. Santos-Arteaga, “A hybrid intelligent fuzzy predictive model with simulation for supplier evaluation and selection," Expert Systems with Applications and International Journal, vol. 61, pp. 129-144. 2016.

[5] S. Luthra, K, Govindan, D. Kannan D, S. K. Mangla, and C. P. Garg, "An integrated framework for sustainable supplier selection and evaluation in supply chains," Journal of Cleaner Production, vol.140, pp. 1686-1698, 2017.

[6] C. Schuh, R. Kromoser, M. F. Strohmer, R. R. Pérez, and Triplat. "The purchasing chessboard," Purchasing Chessboard, pp. 53-201, 2009.

[7] C. Schuh, R. Kromoser, M. F. Strohmer, R. R. Pérez, and Triplat, The Purchasing Chessboard. Springer New York, 2012. 